\title{
EL SIGNIFICADO DE SER DE IZQUIERDAS EN LA ESPAÑA ACTUAL
}

\author{
Juan Díez Medrano \\ The University of Michigan \\ Blanca García-Mon y Juan Díez Nicolás \\ Universidad Complutense de Madrid
}

RESUMEN. El artículo estudia, a nivel teórico, empírico y político, el cambio producido en el significado del autoposicionamiento ideológico en España, partiendo de la aparente contradicción de que los españoles se autoposicionen mayoritariamente en la izquierda y voten a un partido socialista que no practica una política de izquierda tradicional. La explicación que se ofrece y verifica es la de que la polarización política entre derecha e izquierda se basa actualmente más en cuestiones no-económicas (morales y sociales) que en cuestiones cconómicas. Las hipótesis han sido verificadas mediante técnicas de análisis factorial confirmatorio (LISREL), habiéndose especificado, además, que la dimensión moralsocial es aún más importante que la económica entre las generaciones más jóvenes.

\section{Introducción}

Siete años después de la primera victoria socialista en unas elecciones generales, muchos españoles, tanto intelectuales como profanos, se preguntan por el significado real de los programas políticos de derecha y de izquierda, y si existen diferencias profundas entre ellos. Por una parte, el Partido Socialista no parece sentirse amenazado actualmente por ningún partido situado a su izquierda (los comunistas de IU) ni a su derecha (los centristas del CDS o los conservadores del PP). Unicamente en elecciones autonómicas, como por ejemplo en Cataluña y en el País Vasco, los socialistas han sido derrotados por partidos nacionalistas. A pesar de haberse registrado cierto des- 
censo en el voto socialista, la realidad es que mucho españoles prevén la victoria del socialismo durante todavía bastante tiempo. Por último, y como veremos a continuación, los sondeos indican que la mayoría de los entrevistados tienden a considerarse de izquierdas, y ésta parece ser una característica bastante estable de la cultura política de los españoles.

Por otra parte, cuando se analizan las políticas concretas del gobierno socialista, es evidente que éstas no parecen socialistas en absoluto. Cuando los socialistas accedieron al poder en 1982 hicieron una nacionalización simbólica (la del bolding RUMASA) y muy poco más. De hecho, la mayoría de las sociedades que pertenecían al bolding nacionalizado han acabado reprivatizadas tarde o temprano. Pero el significado y las consecuencias reales, a corto y medio plazo, de la nacionalización y posterior reprivatización de RUMASA constituyen de por sí una cuestión oscura y de gran importancia, y no pueden ser debidamente analizadas en este trabajo.

Así, la política económica socialista ha concedido la máxima prioridad al crecimiento económico y al mantenimiento de unos indicadores económicos saludables, al mismo tiempo que se favorecía la liberalización de la economía y en especial la entrada de fuertes y numerosas inversiones de capital extranjero. Aparentemente, ya no está de moda hablar de reducir las desigualdades sociales o de suprimir el patrimonialismo en la Administración Pública. Por lo que respecta a las relaciones internacionales, y a pesar de ciertas tensiones con los Estados Unidos respecto a las bases americanas que existen en territorio español, el gobierno González ha consolidado la integración de España en la OTAN, desdiciéndose así de una de las principales ofertas del programa socialista en la campaña electoral de 1982. $\mathrm{Y}$ no sólo eso, sino que ha integrado a España también en la UEO y ha acabado firmando un acuerdo bilateral de defensa con los Estados Unidos cuyas cláusulas, no suficientemente aclaradas, parecen contradecir (a juicio de la oposición) las condiciones bajo las cuales se aprobó la permanencia de España en la OTAN en el referéndum de 1986.

Desde un punto de vista económico, los resultados de la política socialista han sido generalmente positivos. La tasa de crecimiento anual de la producción industrial española es una de las más altas de los países occidentales desarrollados (aunque inferior a las de Japón y Canadá); la tasa de crecimiento anual del índice de precios al consumo es estable y se sitúa en alrededor del 7 por 100, lo que es sólo algo mayor que el nivel que se encuentra en otros países desarrollados; la balanza de pagos tan sólo representa un pequeño déficit, a pesar del déficit de la balanza comercial, gracias a las inversiones extranjeras (los franceses han llegado a decir que España estaba en venta), al turismo y, todavía, a las remesas de los emigrantes. El principal aspecto negativo de la política económica socialista, analizada en estos términos, es la tasa de desempleo, que permanece próxima al 18 por 100 . Sin embargo, todo el mundo parece estar de acuerdo en que esta tasa esconde 
un fuerte contingente de empleo sumergido, cuya importancia numérica todavía no se ha evaluado correctamente.

Desde un punto de vista social, sin embargo, los resultados de la política socialista han sido más negativos. Los españoles todavía esperan la reforma de la administración pública prometida por los socialistas antes de ganar las elecciones de 1982. La educación y la sanidad sufren una crisis permanente que ha tenido como consecuencia movilizaciones importantes a través de huelgas y manifestaciones contra el gobierno; por último, los servicios públicos básicos, como son el correo, el sistema telefónico o la red nacional de transportes (por carretera, ferrocarril o aéreos), se están deteriorando, porque la demanda de estos servicios excede la oferta existente, sin que se hayan tomado en su momento las decisiones oportunas para su ampliación, conservación y mejora.

Esta redefinición de los objetivos socialistas no siempre se ha realizado sin traumas. Los socialistas han tenido que enfrentarse a disturbios sociales en diferentes momentos de su mandato, y concretamente a manifestaciones anuales de estudiantes reivindicando la reforma del sistema educativo. Al mismo tiempo, el gobierno socialista se ha enfrentado cada vez más a su sindicato, la UGT, liderada por Nicolás Redondo, una de las principales figuras del socialismo antes de la muerte de Franco. UGT afirma que el Partido Socialista ha traicionado a la clase trabajadora a través de una política económica liberalizadora. El Ministro de Economía, Carlos Solchaga, llegó a sugerir en una ocasión el facilitar a las empresas el despido de los trabajadores. El enfrentamiento entre el PSOE y la UGT ha llegado a su máximo nivel con la convocatoria conjunta de Huelga General en toda España, formulada por el sindicato socialista UGT y el comunista CC. OO. en diciembre de 1988 , cuyas repercusiones y consecuencias políticas todavía no han concluido.

La historia de los últimos siete años es, por consiguiente, la historia de una contradicción. Mientras que la mayoría de los españoles votan al Partido Socialista y se autoposicionan en la izquierda, la política socialista se contradice con el socialismo tradicional. Pero esta contradicción sólo lo será si el significado de votar al socialismo y el de definirse de izquierdas o de derechas han permanecido inalterables. Esta es la cuestión que vamos a tratar en este artículo.

Una nueva base para la polarización política

Se ha demostrado que las definiciones de Izquierda/Derecha, Liberal/ Conservador o Laborista/Conservador han sido unos instrumentos mental y literariamente convenientes para englobar una gran variedad de posiciones con respecto a diferentes cuestiones (Downs, 1957; Inglehart y Klingemann, 
1976), y una forma sencilla de caracterizar a los partidos políticos. Tradicionalmente, el concepto de Izquierda ha sido asociado a los de anticlericalismo, cambio social y énfasis en la igualdad, mientras que el concepto de Derecha se ha asociado a los de religiosidad, status quo y énfasis en la libertad. Por lo que respecta a la política económica, la izquierda se ha caracterizado por favorecer las nacionalizaciones y el control gubernamental de la economía, mientras que la derecha suele simbolizar el espíritu de libre empresa y la ausencia de dirigismo estatal (Inglehart, 1989).

Sin embargo, recientemente, se han producido cambios estructurales importantes en los países desarrollados que parecen haber tenido como consecuencia un declive en la popularidad de los ideales tradicionales de la izquierda. Para Inglehart (1989), esto se debe al hecho de que «con la emergencia de la sociedad industrial avanzada, el impacto de los factores económicos alcanza un punto de rendimientos decrecientes. Las cuestiones no económicas adquieren una importancia creciente en los planes y programas nacionales, dando lugar a la aparición de un nuevo eje de polarización politica». Estos nuevos factores no económicos parecerían estar relacionados con la dimensión postmaterialista/materialista, que habría reemplazado a la tradicional división de la sociedad en clases, convirtiéndose en la explicación más importante de las actitudes políticas en varios países occidentales (Inglehart, 1977, 1989) ${ }^{1}$.

Ante este hecho, la reacción de los partidos políticos de izquierda ha variado de unos países a otros. En ciertos casos han mantenido tenazmente sus antiguos programas políticos, como han hecho el Partido Laborista inglés - el Partido Comunista francés. En otros casos, han eliminado de sus programas el dogma tradicional de la izquierda, sin realmente incluir nuevos objetivos en sus programas, intentando así ganar las elecciones mediante la demostración de su competencia en el terreno económico, y desprovistos de ideales políticos claros. Los Partidos Socialistas de España y Francia encajan perfectamente en esta categoría. Por último, algunos partidos de izquierdas tratan de adaptarse al nuevo contexto enterrando antiguas políticas, e incluyendo temas postmaterialistas en sus campañas. Aquí se podría incluir al SPD alemán y al Partido Comunista de España.

Cuando se analizan los resultados políticos, parece que los partidos de izquierdas que han tenido más éxito han sido los que se han dirigido a las clases medias, restando importancia a los temas políticos tradicionales e insistiendo en la competencia económica o en la renovación ideológica.

Volviendo a las actitudes políticas individuales, el cambio en las bases de la polarización política puede encontrarse en varios estudios que intentan evaluar el significado que dan los entrevistados a los conceptos de izquierda

1 Esto está perfectamente explicado en el reciente libro de Inglehart (Inglehart, 1989), por lo que no lo desarrollaremos aquí. 
y derecha. Dos enfoques han sido muy utilizados: el primero se basa en las definiciones que dan los propios entrevistados (Klingemann, 1976; Lambert, Curtis, Brown y Kay, 1986; García Ferrando, 1984); el segundo se basa en técnicas de análisis factorial, mediante las cuales el autoposicionamiento en una escala ideológica se combina con otros items relacionados con distintas cuestiones o con las preferencias políticas (Inglehart y Sidjansk, 1976; Inglehart y Klingemann, 1976; Lambert et al., 1986; McDonough, Barnes y López Pina, 1985). Preferimos el segundo enfoque porque el primero confía excesivamente en la habilidad verbal de los entrevistados en el momento de la entrevista. Sin embargo, existen ciertos peligros inherentes a los estudios que utilizan el análisis factorial. La mayoría de ellos se pueden resumir diciendo que no tienen en cuenta una estructura causal: introducen a la vez preferencias políticas, temas polémicos y variables sociodemográficas, pero no se explican las razones por las que se incluyen ciertos temas y no otros, ni si el modelo de intercorrelaciones entre diferentes conjuntos de temas podría influir sobre los resultados del análisis.

Por este motivo sus conclusiones deben tomarse generalmente con suma cautela. Sin embargo, de estos estudios surgen algunas pautas empíricas.

El autoposicionamiento ideológico está relacionado a la vez con actitudes ante ciertas cuestiones y con preferencias políticas (Inglehart, 1989; Inglehart y Klingemann, 1976; Lambert et al., 1986). En este estudio estamos interesados en la relación que existe entre las actitudes hacia algunas cuestiones y el autoposicionamiento en una escala de ideología. Parece que se ha producido cierta evolución en la dirección sugerida por las hipótesis de Inglehart; aunque las cuestiones económicas puedan haber sido los principales factores diferenciadores (Inglehart y Sidjanski, 1976), los factores no económicos comienzan a ocupar el lugar preferente (Inglehart, 1989). Sin embargo, alguna que otra vez aparecen resultados sorprendentes que contradicen esta proposición (Lambert et al., 1986). Pensamos que estas contradicciones se deben en gran medida a las cuestiones incluidas en el modelo, pero también podrían reflejar un diferente grado de ajuste de las actitudes individuales ante las nuevas condiciones sociales.

En este artículo se pretenden verificar para España algunas de las ideas que se han expuesto anteriormente. Así, centrándonos en la influencia que determinados temas tienen sobre el autoposicionamiento ideológico, evaluaremos el efecto relativo de ciertas cuestiones tradicionales de política económica y de otros temas no económicos. En segundo lugar, prestaremos atención especial al efecto relativo que las diferencias intergeneracionales puedan tener sobre la relación entre los temas económicos y no económicos con el autoposicionamiento ideológico. Si el razonamiento expuesto es correcto, los factores económicos deberían ser más importantes para las generaciones de más edad, mientras que los factores no económicos deberían ser más importantes para las más jóvenes. 


\section{Evolución del autoposicionamiento ideológico en España}

Las investigaciones que se han llevado a cabo sobre el significado del autoposicionamiento ideológico han demostrado reiteradamente que éste está estrechamente relacionado con la identificación con un determinado partido político, especialmente «cuando la leaitad a los partidos es fuerte y la dimensión izquierda/derecha ha sido saliente durante mucho tiempo» (Inglehart y Klingemann, 1976).

También se suele aceptar que existe una relación causal recíproca entre el autoposicionamiento ideológico y los comportamientos electorales, aunque son escasos los estudios que han tratado de estimar la magnitud de ambos efectos, debido a la dificultad de encontrar variables instrumentales adecuadas. Veremos aquí que las tendencias en estas dos dimensiones son bastante paralelas cuando se considera el caso del electorado español, a pesar de que la fidelidad a los diferentes partidos políticos no ha sido muy grande durante este período.

No existen datos fiables sobre el autoposicionamiento ideológico de los españoles antes de 1976 (cuando al morir Franco, en noviembre de 1975, se inició la transición política en España), debido principalmente a que la ausencia de libertades políticas constituía un obstáculo para que los individuos admitiesen ser «de izquierdas». En el otoño de 1976, sin embargo, el gobierno centrista presidido por Adolfo Suárez presentó a las Cortes Españolas el Proyecto de Ley para la Reforma Política, que fue aprobado por el Pleno, por amplia mayoría, el 18 de noviembre de 1976, siendo ratificado por el pueblo español mediante referéndum el 15 de diciembre de 1976. En la medida en que la Ley para la Reforma Política constituyó el primer y decisivo paso para el establecimiento de un sistema político democrático en España, su aprobación por las Cortes permitió ya a los ciudadanos expresar con mayor libertad sus opiniones políticas, aunque es muy posible que muchos de ellos todavía tuvieran ciertos recelos a hacerlo así hasta las primeras elecciones legislativas de junio de 1977, cuando se comprobó que las libertades políticas eran una realidad (ya que todos los partidos políticos, muchos de ellos a la izquierda del Partido Comunista de España, fueron legalizados antes de dichas elecciones).

Por ello, los sondeos realizados por el Instituto de la Opinión Pública desde diciembre de 1976, en los que ya se preguntó a los entrevistados por su autoposicionamiento ideológico, pueden ser considerados como bastante fiables, aunque es posible que la autoubicación en la «izquierda» estuviese aún algo infraestimada hasta las elecciones de junio de 1977, debido a las dudas que ciertos sectores sociales podían todavía tener respecto a la ausencia de riesgo en autocalificarse «de izquierdas» (cuadro 1).

El contexto social y político en el que se desarrolló el comienzo de la transición política estuvo caracterizado por un cierto temor, ampliamente 


\section{CUADRO 1}

Autoposicionamiento ideológico de los españoles, 1976-1988* (En porcentajes)

\begin{tabular}{|c|c|c|c|c|c|c|c|c|c|c|c|c|}
\hline & $X I I-76$ & $V-77$ & $I .79$ & $I I-80$ & $V I-81$ & $X I-82$ & $V-83$ & $\begin{array}{l}I X-84 I \\
V I-85\end{array}$ & $\begin{array}{l}I X-85 / \\
V I-86\end{array}$ & $\begin{array}{c}X-86 / \\
V I I-87\end{array}$ & $\begin{array}{l}X-87 / \\
V I-88\end{array}$ & $\begin{array}{l}X-88 / \\
V I-89\end{array}$ \\
\hline 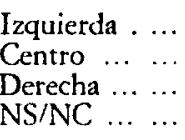 & $\begin{array}{l}17 \\
44 \\
16 \\
23\end{array}$ & $\begin{array}{l}24 \\
30 \\
14 \\
43\end{array}$ & $\begin{array}{r}30 \\
30 \\
9 \\
31\end{array}$ & $\begin{array}{l}37 \\
24 \\
12 \\
27\end{array}$ & $\begin{array}{l}36 \\
21 \\
12 \\
31\end{array}$ & $\begin{array}{l}45 \\
20 \\
18 \\
17\end{array}$ & $\begin{array}{l}47 \\
15 \\
15 \\
23\end{array}$ & $\begin{array}{l}38 \\
18 \\
18 \\
26\end{array}$ & $\begin{array}{l}38 \\
18 \\
17 \\
27\end{array}$ & $\begin{array}{l}40 \\
18 \\
15 \\
27\end{array}$ & $\begin{array}{l}38 \\
15 \\
17 \\
30\end{array}$ & $\begin{array}{l}37 \\
14 \\
14 \\
34\end{array}$ \\
\hline & (1.061) & $(26.067)$ & $(1.196)$ & $(1.190)$ & $(2.394)$ & $(24.734)$ & $(1.200)$ & $(1.200)$ & $(1.200)$ & $(1.200)$ & $(1.200)$ & $(10.901)$ \\
\hline
\end{tabular}

* Cada muestra entre IX.84 y el V1.88 tienen un tamaño $=1.200$. Los datos hasta V.83 proceden del Banco de Datos del CIS (Centro de Investigaciones Sociológicas). Los datos desde IX-84 a VI-86 han sido publicados por OTR/IS en diferentes publicaciones del Grupo Z, especialmente Tiempo e Interviú. Los datos desde X-86 a VI-89 proceden del Banco de Datos de ASEP (Análisis Sociológicos, Económicos y Políticos, S. A.). 
compartido por la mayoría de los españoles, a que el poder que todavía tenían en España los grupos sociales que habían sido el principal soporte del régimen de Franco impidieran o limitaran excesivamente el cambio político hacia la democracia (como había ocurrido bajo el gobierno de Carlos Arias hasta julio de 1976). Además, existía también el temor a que los cambios políticos fuesen demasiado bruscos y rápidos, debido al rechazo del cambio revolucionario en sí mismo, y también a que éstos pudiesen provocar una reacción de las fuerzas sociales más inmovilistas para frenar (e incluso invertir) el proceso de democratización.

Las investigaciones realizadas por el Instituto de la Opinión Pública desde octubre de 1976 demostraron, reiteradamente, que los españoles deseaban mayoritariamente la «reforma» política, rechazando por igual el inmovilismo (la persistencia de las estructuras políticas franquistas) y la revolución (la ruptura, sobre todo violenta, con el régimen anterior). La moderación, entendida como deseos de cambio pacífico y sin revanchas o «ajustes de cuentas», caracterizó a la opinión pública española durante la transición política, desde sus comienzos hasta el presente (Díez Nicolás, 1978).

El comprender este contexto social es necesario para entender la evolución que se ha producido en el autoposicionamiento ideológico de los españoles (CIS, 1977, y Alvira y otros, 1978), que probablemente ha sido más aparente que real. Todos los datos que se comentan a continuación proceden de encuestas basadas en muestras nacionales representativas de la población española que han sido realizadas por diferentes instituciones de investigación, según se indica en el cuadro 1 , en las que se ha seguido siempre la misma metodología?.

La escala de autoposicionamiento ideológico es de siete puntos, y en ella se le especificaba al entrevistado que el 1 correspondía a la extrema izquierda y el 7 a la extrema derecha. Las posiciones intermedias no fueron especificadas en las investigaciones realizadas entre 1976 y 1986, pero a partir de esa fecha fueron especificadas a los entrevistados con el mismo significado que se les había estado atribuyendo habitualmente en el análisis de los datos ${ }^{3}$. Los datos que luego se examinarán parecen demostrar que este hecho no produjo ningún efecto significativo sobre las respuestas de los entrevistados.

El énfasis en la moderación y en la reforma (frente al inmovilismo y la revolución), así como las dudas sobre la legalidad de expresarse con total libertad política, explican que casi la mitad de los entrevistados se autoposicionasen, en diciembre de 1976, exactamente en la posición central de la

2 Las encuestas fueron representativas de la población española mayor de 21 años hasta principios de 1979. Pero en las elecciones generales de 1979 la edad de votar se redujo a los 18 años, lo que obligó a modificar también la edad de la muestra, para mantener su carácter representativo de la población con derecho a votar, que a partir de esa fecha incluyó a la población mayor de 18 años.

${ }^{3}$ La equivalencia es: 1 = extrema izquierda; $2=$ izquierda; 3 = centro izquierda; $4=$ centro; $5=$ centro derecha; $6=$ derecha; $7=$ extrema derecha. 
escala y que proporciones semejantes se autoposicionasen en las tres posiciones de izquierda $(1,2$ y 3$)$ o en las tres de derecha $(5,6 \text { y } 7)^{4}$. Todos los estudios coincidían en señalar que la mayoría de los españoles querían el cambio político, pero no un cambio revolucionario. En los primeros momentos de la transición política, la izquierda (comunistas y socialistas) era considerada como defensora de cambios muy radicales, en las estructuras políticas, económicas y sociales. Por todas estas razones, parece explicable la victoria del partido de centro (UCD) en las primeras elecciones democráticas de junio de 1977; este partido, al insistir en su ideología de centro y al protagonizar el proceso de reforma política, parecía garantizar la moderación y la prudencia en los cambios políticos, económicos y sociales.

Poco antes de dichas elecciones, sin embargo, la proporción de españoles que se autoposicionaba en el centro en la escala de ideología se había reducido a un tercio, y era sólo algo superior a la que se posicionaba en la izquierda. Probablemente este hecho indica que los entrevistados por fin creyeron que la reforma política era sincera y se sintieron libres para expresar sus opiniones, especialmente cuando todos los partidos políticos fueron legalizados antes de estas elecciones. También puede obedecer este hecho a la existencia de un mayor conocimiento de la opinión pública sobre las posiciones y programas de los diferentes partidos políticos. La legalización de tantos partidos políticos $(67$ partidos participaron en las primeras elecciones democráticas) posiblemente tuvo un doble efecto. Por una parte, puede que este hecho ayudase a mucha gente a saber cuál era la actitud de los diferentes partidos respecto a las diferentes cuestiones políticas. Algunos de ellos no eran tan revolucionarios como se pensaba, y esto pudo inducir a mucha gente a apoyarlos, adoptando simultáneamente su etiqueta ideológica de izquierda. Por otra parte, puede que este hecho provocase cierta confusión, lo que explicaría el incremento en la proporción de entrevistados que, en vísperas de las elecciones de 1977, no contestaron cuando se les pidió que se posicionaran en una escala de ideología. En cualquier caso, los resultados electorales de 1977 se adecuaron bastante a la distribución de los españoles según su autoposicionamiento ideológico (cuadro 2).

Poco antes de las elecciones de 1979 se había acentuado aún más el autoposicionamiento de los españoles hacia la izquierda, cuyo peso era ya equivalente al del centro. Este hecho se puso de manifiesto en los resultados electorales de marzo de 1979. Para esa fecha, parecía ya claro que la opinión pública no deseaba identificarse con la derecha, y ello se tradujo en la exigua proporción de votos que logró el partido conservador, Alianza Popular (entonces Coalición Democrática), en esas elecciones.

- Muchos autores atribuyen a una falta de conocimiento de los entrevistados la tendencia a escoger la posición media $y$, por ello, prefieren una escala sin punto medio (Lambert, 1983; Inglehart y Klingermann, 1976; Deutch, Lindon y Weill, 1966). 


\section{CUADRO 2}

Resultados de las Elecciones Generales, 1977-1986* (En porcentajes)

\begin{tabular}{|c|c|c|c|c|}
\hline & $V I-1977$ & III-1979 & $X-1982$ & $V I .1986$ \\
\hline 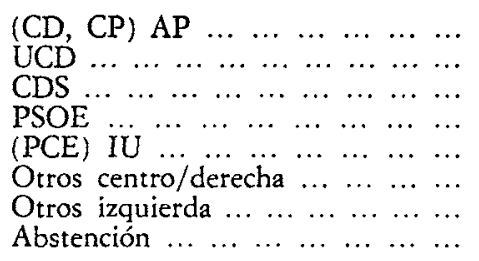 & $\begin{array}{r}6,1 \\
26,8 \\
\overline{22,8} \\
7,2 \\
8,1 \\
6,5 \\
22,5\end{array}$ & $\begin{array}{r}4,0 \\
23,5 \\
20,4 \\
7,2 \\
5,1 \\
6,9 \\
32,9\end{array}$ & $\begin{array}{r}20,7 \\
5,3 \\
2,2 \\
37,6 \\
3,2 \\
5,3 \\
3,6 \\
22,1\end{array}$ & $\begin{array}{r}18,1 \\
6,4 \\
30,7 \\
3,2 \\
7,2 \\
3,6 \\
30,8\end{array}$ \\
\hline 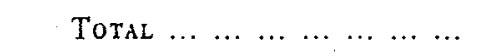 & 100,0 & 100,0 & 100,0 & 100,0 \\
\hline $\begin{array}{llllllll}\text { Izquierda } & \ldots & \ldots & \ldots & \ldots & \ldots & \ldots & \ldots \\
\text { Centro/derecha } & \ldots & \ldots & \ldots & \ldots & \ldots & \ldots\end{array}$ & $\begin{array}{l}36,5 \\
41,0\end{array}$ & $\begin{array}{l}34,5 \\
32,6\end{array}$ & $\begin{array}{l}44,4 \\
33,5\end{array}$ & $\begin{array}{l}37,5 \\
31,7\end{array}$ \\
\hline
\end{tabular}

* Los datos proceden de los resultados publicados por el Ministerio del Interior después de cada elección, y han sido reelaborados por J. Díez Nicolás después de la clasificación de los partidos como de izquierda o como de centro o derecha. Véase, a este respecto, Diez Nicolás, 1984 y 1986.

El equilibrio en la distribución de votos entre el partido de centro (UCD) y el Partido Socialista (PSOE) creó tensiones en UCD que, finalmente, llevaron a su desaparición como fuerza política. Esta conmoción política posiblemente tuvo algún efecto independiente sobre la continua reducción en la proporción de entrevistados que se autoposicionaban en el centro, observable desde entonces, y puede que explique el espectacular incremento de quienes se identifican como de izquierda (y especialmente como de centro/izquierda). Otro factor importante que explica este último fenómeno es la moderación simultánea del Partido Socialista durante esos años; desde un punto de vista simbólico, el punto de inflexión fue la decisión de eliminar la etiqueta marxista del programa del Partido Socialista en su XXIX Congreso de 1979. Así, en febrero de 1980, la proporción de quienes se autoposicionaban en la izquierda era algo mayor que la que se autoposicionaba conjuntamente en el centro o en la derecha. Por comparación con diciembre de 1976, los datos de febrero de 1980 mostraban que se había duplicado el peso relativo de la izquierda, al tiempo que se había reducido a la mitad el del centro, disminuyendo también en un 25 por 100 el peso relativo de la derecha. Esta tendencia se agudizó aún más en 1981 y 1982, hasta el punto de que, poco antes de las elecciones de octubre de 1982, casi la mitad del electorado se autoubicaba en la izquierda. Los resultados de dichas elecciones, en las que 
el PSOE logró la mayoría absoluta, confirmaron estos cambios de identificación ideológica, e inciuso los reforzaron aún más, como parecen poner de manifiesto los datos de $\mathrm{V}-83$, fecha en que la izquierda parece haber alcanzado su máximo, y el centro el mínimo.

Después de los dos primeros años de gobierno socialista, sin embargo, y una vez que los ciudadanos comprobaron que seguía funcionando el sistema democrático, y también posiblemente a causa del desgaste del socialismo por el ejercicio del poder, las anteriores tendencias se suavizaron ligeramente. No obstante, los datos promedio para estos últimos cinco años idesde septiemibre de 1984 a junio de 1989), basados en unos diez sondeos mensuales por año, muestran una pauta de distribución muy estable, en la que el peso de quienes se autoposicionan en la izquierda es algo superior al de quienes se autoposicionan conjuntamente en el centro o en la derecha, siendo estas dos últimas proporciones bastante semejantes entre sí. Puede incluso advertirse, en este último período 1987-89, cierta disminución de quienes se autoposicionan en el centro, por comparación con quienes lo hacen en la derecha, que podría responder a la aparente dificultad del CDS, como partido de centro, para representar una alternativa real al PSOE, como en su momento la representó UCD ${ }^{5}$.

En resumen, los cambios en el autoposicionamiento ideológico han sido bastante inestables (aunque parecen haber seguido una pauta hacia la izquierda), y parecen haber estado muy relacionados con las tendencias electorales. La desorganización de los partidos de centro y de los conservadores, así como la progresiva moderación de los partidos tradicionalmente llamados de izquierda, podrían explicar la victoria electoral socialista, así como el incremento de la proporción de españoles que se autoposicionan en la izquierda en la escala de ideología. Preguntar por los factores que polarizan a la opinión pública española en la escala de ideología es como preguntar por los rasgos que diferencian a los votantes socialistas o comunistas de los votantes de los partidos de centro o conservadores.

"Es también posible que la progresiva pérdida de «imagen» social del término derecha y la simultánea creciente aceptación del término izquierda hayan provocado un desplazamiento de toda la escala hacia la izquierda. En efecto, los datos del CIS (1986) demuestran que, entre 1979 y 1982, los españoles se autoubicaban preferentemente en el centro o en el centro/izquierda (entre un $20-25$ por 100 en cada una de esas posiciones), siendo generalmente inferiores al 10 por 100 las proporciones que se autoubicaban en cualquiera de las otras cinco posiciones. Por el contrario, los datos correspondientes a los tres últimos años (X-86 a VI-89) demuestran que la mayor proporción es la que se posiciona en la izquierda (19-22 por 100), algo menos en el centro/izquierda (17-18 por 100) y algo menos aún en el centro (15-19 por 100). 


\section{Datos}

Los datos utilizados para este artículo provienen de una encuesta por muestreo a 1.204 personas que representan a la población española de dieciocho y más años, realizada por ASEP en marzo de $1985^{\circ}$. El modelo que se ha analizado para predecir el autoposicionamiento ideológico de los entrevistados consta de siete indicadores, además de la edad y la educación de los entrevistados.

En primer lugar, se han incluido varios items destinados a medir las actitudes del entrevistado respecto a cuestiones de índole social y moral:

- Práctica religiosa: Una escala de tres puntos, que mide la práctica religiosa, desde muy frecuente hasta inexistente.

- Actitud hacia la cobabitación: Una escala de cuatro puntos, cuyo valor mínimo (1) indica una actitud muy favorable, y el valor máximo (4) una actitud muy desfavorable.

- Indice de postmaterialismo: Un índice de ocho puntos, basado en las respuestas a cuatro baterías de preguntas relativas a los objetivos sociales a los que España debería dar prioridad en los próximos diez años. Las tres primeras baterías constan de cuatro alternativas, de entre las cuales el entrevistado debía elegir el objetivo más importante y el segundo más importante. Esas tres primeras listas de objetivos, basadas en el trabajo pionero del profesor Ronald Inglehart (1977), fueron las siguientes:

\section{Batería 1:}

1. Mantener un alto nivel de crecimiento económico.

2. Tener unas Fuerzas Armadas poderosas y modernas.

3. DAR A LA GENTE MAYORES FACILIDADES PARA QUE PARTICIPE EN LAS DECISIONES IMPORTANTES QUE TENGAN QUE VER CON SU TRABAJO O LA COMUNIDAD EN QUE SE VIVE.

4. MANTENER LAS CIUDADES Y LOS PUEBLOS MAS BONITOS Y CUIDADOS.

\section{Batería 2:}

1. Mantener el orden en la sociedad.

2. DAR A LA GENTE MAYORES POSIBILIDADES DE PARTTCIPACION EN LAS DECISIONES GUBERNAMENTALES O POLITICAS DE CARACTER IMPORTANTE.

- Análisis Sociológicos, Económicos y Politicos, S. A. 
3. Luchar contra la subida de los precios.

4. PROTEGER LA LIBERTAD DE EXPRESION.

\section{Batería 3:}

1. Mantener una economía estable.

2. AVANZAR HACIA UNA SOCIEDAD MENOS IMPERSONAL Y MAS HUMANA.

3. AVANZAR HACIA UNA SOCIEDAD EN LA QUE LAS IDEAS SEAN MAS IMPORTANTES QUE EL DINERO.

4. Luchar contra la delincuencia.

La cuarta lista de objetivos incluía las doce opciones sugeridas en las tres primeras baterías. El entrevistado debía elegir el primero y el segundo objetivo más importantes de los doce propuestos. Sobre la base de estas respuestas, se construye el índice de postmaterialismo, mediante la suma del número de opciones postmaterialistas (en letras mayúsculas) elegidas por el entrevistado en esas cuatro baterías. No es éste el lugar adecuado para discutir en profundidad lo apropiado del término postmaterialismo o sus diversas formas de operacionalización ${ }^{7}$ (Inglehart, 1977), pero puede señalarse que a lo largo de estos últimos años los valores de dicho índice han experimentado un crecimiento continuo en la mayoría de los países occidentales, habiéndose revelado como una de las variables más importantes en la predicción de actitudes y comportamientos políticos.

El modelo incluye también una serie de variables de carácter económico, tradicionalmente defendidas por las formaciones de carácter marxista:

- Actitud hacia la nacionalización de la Banca.

- Actitud hacia un mayor número de nacionalizaciones de empresas

- Actitud hacia un mayor papel del gobierno en la dirección de la economía.

Estas tres preguntas constaban de cinco posibles respuestas (excepto la primera), desde un grado de máximo acuerdo (1) a un grado de máximo desacuerdo (5).

No se ha seleccionado otra pregunta incluida en el cuestionario - - la actitud hacia la reducción de las desigualdades - por ser excesivamente vago el planteamiento (es fácil responder que se está de acuerdo cuando no se precisa a través de qué medidas) y por no existir una variación sustancial en las respuestas dadas por los entrevistados (ya que la inmensa mayoría se mostraba de acuerdo en reducir las citadas desigualdades).

Se han usado diferentes enfoques para crear el índice de postmaterialismo, pero casi invariablemente se ha llegado a los mismos resultados. 
Finalmente, la variable dependiente de este análisis es el autoposicionamiento ideológico, basado en la escala de siete puntos ya explicada.

\section{Metodología}

El procedimiento elegido para analizar los datos es el análisis factorial confirmatorio (Joreskog y Sorbom, 1979, 1983). El objetivo de este análisis es estimar los efectos relativos de las actitudes morales y sociales del entrevistado, así como de sus actitudes hacia ciertas cuestiones de política económica, sobre su autoposicionamiento ideológico. Cada uno de los factores latentes independientes ha sido medido por tres indicadores, como se ha señalado anteriormente. En teoría, podría haber interesado medir el efecto rclativo de las diferentes subdimensiones del factor latente Moral y Social (actitudes religiosas, actitudes ante la familia, objetivos sociales). Lamentablemente, estas actitudes están íntimamente relacionadas entre sí, y no parece aconsejable evaluar sus efectos relativos. Un diseño de investigación diferente que maximizase la independencia estadística de las tres subdimensiones sería más apropiado para esta tarea. En la figura 1 se presenta el modelo que se ha diseñado.

\section{Análisis}

Descripción de la muestra y de la submuestra analizada.

A continuación se describen las principales características de esta muestra en relación con las variables utilizadas en el análisis. Los entrevistados que se declaran muy practicantes (cuadro 3 ) desde el punto de vista religioso

\section{CUADRO 3}

Práctica religiosa

\begin{tabular}{|c|c|c|c|c|c|}
\hline Categorias & Valores & Frecuencias & Porcentajes & $\begin{array}{c}\text { Porcentajes } \\
\text { válidos }\end{array}$ & $\begin{array}{l}\text { Porcentajes } \\
\text { acumulados }\end{array}$ \\
\hline Muy practicante . ... & 1 & 244 & 20,3 & 21,0 & 21,0 \\
\hline Poco practicante.... & 2 & 472 & 39,2 & 40,5 & 61,5 \\
\hline Nada practicante.... & 3 & 448 & 37,2 & 38,5 & 100,0 \\
\hline NS/NC $\ldots \ldots \ldots$ & 9 & 40 & 3,3 & - & \\
\hline $\begin{array}{lllll}N & \ldots & \ldots & \ldots & \ldots\end{array}$ & & 1.204 & 100,0 & 100,0 & \\
\hline
\end{tabular}




\section{FIGURA 1}

Modelo estructural para la estimación de los efectos de cuestiones económicas y no económicas sobre el autoposicionamiento ideológico

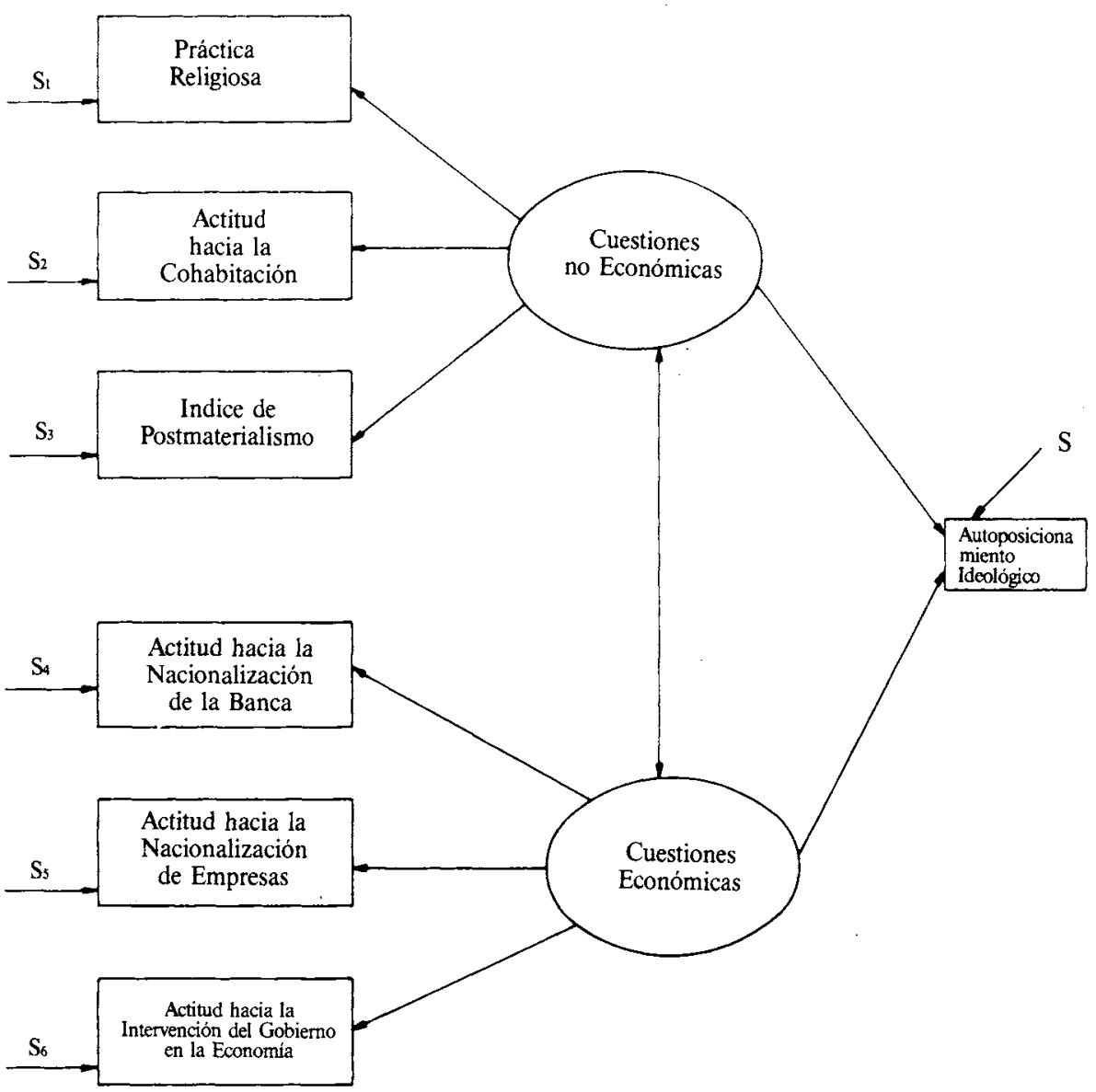

(20,3 por 100 sobre el total de los entrevistados; 21 por 100 sobre el total de respuestas válidas) están lejos de representar una mayoría; aunque la mediana de la práctica religiosa se sitúa entre las categorías de poco practicante y muy practicante, el porcentaje de los que se declaran «nada practicantes» $(37,2$ ó 38,5 por 100$)$ es superior al de los que se declaran muy practicantes $(20,3$ ó 21,0 por 100$)$. 
Un análisis de regresión múltiple con la edad y la educación como va. riables independientes pone de manifiesto que la religiosidad está positivamente relacionada con la edad, mientras que la educación no tiene un efecto estadísticamente significativo, cuando se controla por la edad (cuadro 4).

\section{CUADRO 4}

Efecto de la edad y de la educación en cuestiones no económicas $y$ en cuestiones económicas

\begin{tabular}{|c|c|c|c|c|c|c|c|}
\hline & (1) & (2) & (3) & (4) & (5) & (6) & (7) \\
\hline Intercepción . ... & $2,97 *$ & $1,03 *$ & $3,06 *$ & $1,86 *$ & $2,09 *$ & $2.17 *$ & 2,34 * \\
\hline $\operatorname{Edad} \ldots \ldots \ldots \ldots$ & $-0,01 *$ & $0,02 *$ & 0,01 & $0,01 *$ & $0,01 *$ & 0,00 & $0,02 *$ \\
\hline Educación $\ldots \ldots$ & 0,00 & $-0,02$ & $0,22 *$ & $0,09 *$ & $0,09 \div$ & $0,05 *$ & 0,05 \\
\hline R Cuadrado ....... & 0,05 & 0,23 & 0,13 & 0,03 & 0,04 & 0,01 & 0,05 \\
\hline$N=404$ & & & & & & & \\
\hline
\end{tabular}

* Significativo en el nivel 0,5 .

(1) Práctica religiosa.

(2) Actitudes ante la cohabitación.

(3) Indice de postmaterialismo.

(4) Actitudes ante la nacionalización de bancos.

(5) Actitudes ante la nacionalización de empresas privadas.

(6) Actitudes ante el aumento del control del Estado sobre la economía.

(7) Autoposicionamiento ideológico.

Nota: Se presentan coeficientes estandarizados.

Teniendo en cuenta que éste es un análisis transversal, es difícil determinar si el efecto de la edad constituye un efecto de cohorte o un efecto de ciclo vital, aunque la evidencia disponible en otros estudios sugiere que el efecto de cohorte es más importante que el efecto de ciclo vital.

Además, los entrevistados se muestran ligeramente a favor de la cohabitación (cuadro 5): un 57,4 por 100 de los entrevistados que opinan sobre el tema está algo o muy a favor (51,4 por 100 sobre el total de entrevistados) y un 24,6 por 100 se declaran muy en contra de la cohabitación. En resumen, parece que la cohabitación va adquiriendo una aceptación social importante que, indudablemente, contrasta con el pequeño porcentaje de parejas que de hecho cohabitan en España. 


\section{CUADRO 5}

Actitudes ante la cobabitación

\begin{tabular}{|c|c|c|c|c|c|}
\hline Calegorias & Valores & Frecuencias & Porcentajes & $\begin{array}{c}\text { Porcentajes } \\
\text { válidos }\end{array}$ & $\begin{array}{l}\text { Porcentajes } \\
\text { acumulados }\end{array}$ \\
\hline Muy a favor $\ldots \ldots$ & 1 & 280 & 23,2 & 25,9 & 25,9 \\
\hline Algo a favor ... ... & 2 & 339 & 28,2 & 31,4 & 57,4 \\
\hline Algo en contra ....... & 3 & 195 & 16,2 & 18,1 & 75,4 \\
\hline Muy en contra ... ... & 4 & 265 & 22,0 & 24,6 & 100,0 \\
\hline NS/NC $\ldots \ldots \ldots c$ & 9 & 125 & 10,4 & 一 & \\
\hline$N \ldots \ldots \ldots$ & & 1.204 & 100,0 & 100,0 & \\
\hline
\end{tabular}

La edad se relaciona negativamente con la aceptación de la cohabitación cuando se controla por la educación, mientras que el efecto de la educación, controlando por la edad, no es significativo desde el punto de vista estadístico. Una vez más, la evidencia sugiere un efecto de cohorte (cuadro 4).

En tercer lugar, se examina el nivel de postmaterialismo que prevalece entre los entrevistados (cuadro 6).

\section{CUADRO 6}

Indice de postmaterialismo

\begin{tabular}{|c|c|c|c|c|c|}
\hline Categorias & Valores & Frecuencias & Porcentajes & $\begin{array}{c}\text { Porcentajes } \\
\text { válidos }\end{array}$ & $\begin{array}{l}\text { Porcentajes } \\
\text { acumulados }\end{array}$ \\
\hline \multirow{9}{*}{ Mínimo $\ldots \ldots \ldots \ldots$} & 0,00 & 118 & 9,8 & 10,0 & 10,0 \\
\hline & 1,00 & 203 & 16,9 & 17,1 & 27,1 \\
\hline & 2,00 & 233 & 19,4 & 19,7 & 46,8 \\
\hline & 3,00 & 211 & 17,5 & 17,8 & 64,6 \\
\hline & 4,00 & 207 & 17,2 & 17,5 & 82,0 \\
\hline & 5,00 & 108 & 9,0 & 9,1 & 91,1 \\
\hline & 6,00 & 64 & 5,3 & 5,4 & 96,5 \\
\hline & 7,00 & 28 & 2,3 & 2,4 & 98,9 \\
\hline & 8,00 & 13 & 1,1 & 1,1 & 100,0 \\
\hline Máximo $\ldots \ldots \ldots \ldots$ & 9,00 & 19 & 1,6 & 一 & \\
\hline Toral ....... & & 1.204 & 100,0 & 100,0 & \\
\hline
\end{tabular}


Los entrevistados tienden a ser más bien materialistas, ya que un 82 por $100(80,8$ por 100 sobre el total de entrevistas) obtiene valores inferiores a 5 en dicha escala. El efecto de la educación sobre el postmaterialismo es positivo y significativo, mientras que el efecto de la edad, controlando por la educación, no es estadísticamente significativo.

Por lo que se refiere a las preguntas sobre temas económicos, lo que más destaca es el alto porcentaje de «no sabe/no contesta» (para este tema, véase $\mathrm{McD}$ onough et al., 1986), así como el elevado porcentaje de personas que se muestran indiferentes ante esos temas. En primer lugar, se observa que un 46,3 por 100 de los entrevistados no responden a la pregunta sobre la nacionalización de la Banca (cuadro 7). De entre los que responden, un 55,9 por 100 está algo de acuerdo (un 29,9 por 100 sobre el total de entrevistados).

CUADRO 7

Actitudes ante la nacionalización de bancos

\begin{tabular}{|c|c|c|c|c|c|}
\hline Categorias & Valores & Frecuencias & Porcentajes & $\begin{array}{c}\text { Porcentajes } \\
\text { válidos }\end{array}$ & $\begin{array}{l}\text { Porcentaies } \\
\text { acumulados }\end{array}$ \\
\hline Muy a favor & 1 & 92 & 7,6 & 14,2 & 14,2 \\
\hline Algo a favor & 2 & 269 & 22,3 & 41,6 & 55,9 \\
\hline Algo en contra ....... & 3 & 156 & 13,0 & 24,1 & 80,0 \\
\hline Muy en contra ....... & 4 & 129 & 10,7 & 20,0 & 100,0 \\
\hline $\begin{array}{lllll}\mathrm{NS} / \mathrm{NC} & \ldots & \ldots & \ldots & \ldots\end{array}$ & 9 & 558 & 46,3 & - & \\
\hline $\begin{array}{lllll}N & \ldots & \ldots & \ldots & \ldots\end{array}$ & & 1.204 & 100,0 & 100,0 & \\
\hline
\end{tabular}

En segundo lugar, un 33,7 por 100 de los encuestados no sabe o no contesta a la pregunta sobre actitud ante la conveniencia de que se produzcan más «nacionalizaciones de empresas privadas». Un 6,8 por 100 adicional

\section{CUADRO 8}

Actitudes ante más nacionalizaciones de empresas privadas

\begin{tabular}{|c|c|c|c|c|c|}
\hline Categorias & Valores & Frecuencias & Porcentajes & $\begin{array}{c}\text { Porcentajes } \\
\text { válidos }\end{array}$ & $\begin{array}{l}\text { Porcentajes } \\
\text { acumulados }\end{array}$ \\
\hline Muy a favor $\ldots \ldots$ & 1 & 66 & 5,5 & 8,3 & 8,3 \\
\hline Algo a favor ....... & 2 & 323 & 268 & 40,5 & 48,7 \\
\hline Indiferente $\ldots \ldots \ldots$ & 3 & 82 & 6,8 & 10,3 & 59,0 \\
\hline Algo en contra $\ldots \ldots$ & 4 & 241 & 20,0 & 30,2 & 89,2 \\
\hline Muy en contra ... ... & 5 & 86 & 7,1 & 10,8 & 100,0 \\
\hline $\mathrm{NS} / \mathrm{NC} \quad \ldots \ldots c c c c$ & 9 & 406 & 33,7 & 一 & \\
\hline $\begin{array}{lllll}N & \ldots & \ldots & \ldots & \ldots\end{array}$ & & 1.204 & 100,0 & 100,0 & \\
\hline
\end{tabular}


se muestra indiferente. $Y$ del 66,3 por 100 de entrevistados que manifiestan una opinión (incluyendo a los que se muestran indiferentes), un 48,7 por 100 está algo a favor o muy a favor (32.3 por 100 del total de entrevistados).

Finalmente, un 26,4 por 100 de los entrevistados no responden a la pregunta sobre su actitud ante un mayor «intervencionismo gubernamental en la dirección de la economía». Un 6,3 por 100 adicional se muestra indiferente. El 68,2 por 100 de los que responden se muestra algo a favor o muy a favor de que aumente el intervencionismo (un 50,2 por 100 del total de entrevistados).

\section{CUADRO 9}

Actitudes ante una mayor participación del gobierno en la economia

\begin{tabular}{|c|c|c|c|c|c|}
\hline Categorias & Valores & Frocuencias & Porcentuies & $\begin{array}{c}\text { Porcentajes } \\
\text { válidos }\end{array}$ & $\begin{array}{l}\text { Porcentajes } \\
\text { acumutados }\end{array}$ \\
\hline 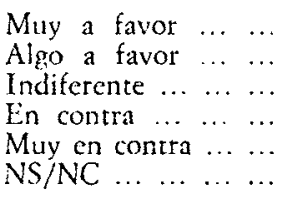 & $\begin{array}{l}1 \\
2 \\
3 \\
4 \\
5 \\
9\end{array}$ & $\begin{array}{r}124 \\
480 \\
76 \\
164 \\
42 \\
318\end{array}$ & $\begin{array}{r}10,3 \\
39,9 \\
6,3 \\
13,6 \\
3,5 \\
26,4\end{array}$ & $\begin{array}{r}14,0 \\
54,2 \\
8,6 \\
18,5 \\
4,7 \\
-\end{array}$ & $\begin{array}{r}14,0 \\
68,2 \\
76,7 \\
95,3 \\
100,0\end{array}$ \\
\hline $\begin{array}{lllll}N & \ldots & \ldots & \ldots & \ldots\end{array}$ & & 1.204 & 100,0 & 100,0 & \\
\hline
\end{tabular}

En resumen, y por lo que respecta a algunas de las banderas del izquierdismo tradicional, los datos sugieren que la población española o no se interesa o no ha estado informada adecuadamente sobre ellas. La imagen que se obtiene de la réación de estas actitudes con la ideología de la población es diferente según se tomen en cuenta todos los entrevistados o sólo los que contestan. En el primer caso, la respuesta que se obtiene es la de que la economía de mercado goza de una aceptación mayoritaria en nuestra sociedad. En el segundo, sin embargo, parece que existe un mayor radicalismo de la población. De hecho, datos de otros países, basados en respuestas válidas, sugieren que el nivel de radicalismo observado en España se corresponde bastante bien con su nivel de desarrollo económico (Inglehart, 1989).

Del mismo modo, cuando se consideran los efectos controlados de la edad y la educación sobre estas variables, se observa que los de más edad y los de mayor nivel educativo tienden a ser más conservadores, aunque el efecto de la educación es algo mayor que el de la edad. El significativo efecto de la educación se debe probablemente a que se trata de cuestiones que afectan a la estructura de clases de la sociedad más directamente que 
los temas de orden moral comentados anteriormente, como la práctica religiosa o las actitudes ante la cohabitación.

Por último, deben hacerse algunas observaciones respecto al autoposicionamiento ideológico de los entrevistados (cuadro 10). El porcentaje de «no sabe/no contesta» es elevado y mayor que en otros países $(34,8$ por 100$)$ (Inglehart y Klingemann, 1976). Al mismo tiempo, los españoles tienden a posicionarse en el centro/izquierda. Un 74 por 100 de los entrevistados que contestan se sitúan en las posiciones de centro, centro/izquierda e izquierda (48 por 100 del total de entrevistados).

\section{CUADRO 10}

Autoposicionamiento ideológico

\begin{tabular}{|c|c|c|c|c|c|}
\hline Callegortas & Valores & Frecuencias & Porcontajes & $\begin{array}{c}\text { Porcentajes } \\
\text { válidos }\end{array}$ & $\begin{array}{l}\text { Poricntales } \\
\text { actmmalados }\end{array}$ \\
\hline Extrema izquierda ... & 1 & 24 & 2,0 & 3,1 & 3,1 \\
\hline $\begin{array}{llll}\text { Izquierda } & \ldots & \ldots & \ldots\end{array}$ & 2 & 201 & 16,7 & 25,6 & 28,7 \\
\hline Centro/izquierda .... & 3 & 183 & 15,2 & 23,3 & 52,0 \\
\hline $\begin{array}{lllll}\text { Centro } & \ldots & \ldots & \ldots & \ldots\end{array}$ & 4 & 197 & 16,4 & 25,1 & 77,1 \\
\hline Centro/derecha , ... & 5 & 81 & 6,7 & 10,3 & 87.4 \\
\hline Derecha $\ldots \ldots \ldots \ldots$ & 6 & 89 & 7,4 & 11,3 & 98,7 \\
\hline Extrema derecha .... & 7 & 10 & 0,8 & 1,3 & 100,0 \\
\hline NS/NC $\ldots \ldots \ldots c c$ & 9 & 419 & 34,8 & - & \\
\hline $\begin{array}{lllll}N & \ldots & \ldots & \ldots & \ldots\end{array}$ & & 1.204 & 100,0 & 100,0 & \\
\hline
\end{tabular}

Esta información contradice en parte lo que ya hemos visto sobre las actitudes hacia las medidas económicas que tradicionalmente se asocian a la izquierda. Sin embargo, como hemos visto, esto puede deberse al hecho de que los que votan al Partido Socialista tienden a autodefinirse como de izquierdas ${ }^{8}$, y a que los que se autoposicionan en la izquierda o centro/ izquierda afirman tener intención de votar al Partido Socialista en mayor proporción que a cualquier otro partido.

${ }^{*}$ De hecho, se ha comprobado que la asociación entre voto e ideología que se describió en el nivel agregado está también presente a nivel individual, como se muestra en el cuadro 11, aunque por razones de espacio no se ha entrado en el análisis pormenorizado de esta cuestión. 
CUADRO 11 (1)

Intención de voto por autoposicionumiento idcológico

(En porcentajes)

\begin{tabular}{|c|c|c|c|c|c|c|}
\hline \multirow[b]{2}{*}{ Intención de volo } & \multicolumn{6}{|c|}{ AUTOPOSICIONAMIENTO IDFOIOGICO } \\
\hline & $\begin{array}{l}\text { Ext. izq. } \\
+ \text { +izquierda }\end{array}$ & $\begin{array}{l}\text { Centrol } \\
\text { izquierda }\end{array}$ & Centro & $\begin{array}{l}\text { Centro! } \\
\text { derecha }\end{array}$ & $\begin{array}{l}\text { Ext der. } \\
\text { + derecha }\end{array}$ & $N S / N C$ \\
\hline $\begin{array}{llllllllllll}A P & \ldots & \ldots & \ldots & \ldots & \ldots & \ldots & \ldots & \ldots & \ldots & \ldots & \ldots\end{array}$ & $* \%$ & $1 \%$ & 60 & $33 \%$ & $56 \%$ & $2 \%$ \\
\hline 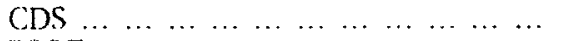 & 2 & 8 & 35 & 19 & 7 & 5 \\
\hline $\begin{array}{lllllllllll}\operatorname{PSOE} & \ldots & \ldots & \ldots & \ldots & \ldots & \ldots & \ldots & \ldots & \ldots & \ldots\end{array}$ & 41 & 56 & 20 & 7 & 6 & 17 \\
\hline $\begin{array}{llllllllllll} & I U & \ldots & \ldots & \ldots & \ldots & \ldots & \ldots & \ldots & \ldots & \ldots & \ldots\end{array}$ & 23 & 4 & 1 & - & - & $*$ \\
\hline Otros $\ldots \ldots \ldots \ldots \ldots \ldots \ldots$ & 13 & 5 & 10 & 15 & 5 & 6 \\
\hline $\begin{array}{llllllllll}\text { No } v \operatorname{votará} & \ldots & \ldots & \ldots & \ldots & \ldots & \ldots & \ldots & \ldots & \ldots\end{array}$ & 8 & 4 & 8 & 7 & 12 & 22 \\
\hline $\begin{array}{llllllllllll} & N S / N C & \ldots & \ldots & \ldots & \ldots & \ldots & \ldots & \ldots & \ldots & \ldots & \ldots\end{array}$ & 13 & 22 & 20 & 19 & 14 & 48 \\
\hline Total $\ldots \ldots \ldots \ldots \ldots \ldots$ & $(231)$ & $(189)$ & $(197)$ & (83) & $(97)$ & $(406)$ \\
\hline$=$ Menos del 1 por 100 & & & & & & \\
\hline
\end{tabular}


CUADRO 11 (II)

Autoposicionamiento ideológico por intención de voto

(En porcentajes)

INTENCION DE VOTO

\begin{tabular}{|c|c|c|c|c|c|c|c|}
\hline \multirow[b]{2}{*}{ Intención de voto } & \multicolumn{7}{|c|}{ INTENCION DE VOTO } \\
\hline & $A P$ & $C D S$ & PSOE & $I U$ & Otros & No votará & $N S / N C$ \\
\hline Extrema izquierda + izquierda $\ldots \ldots \ldots$ & $1 \%$ & $3 \%$ & $29 \%$ & $85 \%$ & $29 \%$ & $12 \%$ & $9 \%$ \\
\hline $\begin{array}{llllllllll}\text { Centro/izquierda } & \ldots & \ldots & \ldots & \ldots & \ldots & \ldots & \ldots\end{array}$ & 1 & 12 & 33 & 11 & 10 & 6 & 12 \\
\hline $\begin{array}{llllllllllll}\text { Centro } & \ldots & \ldots & \ldots & \ldots & \ldots & \ldots & \ldots & \ldots & \ldots & \ldots\end{array}$ & 12 & 53 & 12 & 1 & 21 & 11 & 12 \\
\hline Centro $/$ derecha $\ldots \ldots \ldots \ldots \ldots \ldots \ldots$ & 26 & 12 & 2 & - & 12 & 4 & 5 \\
\hline Extrema derecha + derecha $\ldots \ldots \ldots \ldots$ & 51 & 5 & 2 & - & 5 & 7 & 4 \\
\hline 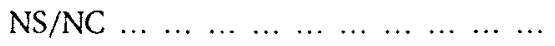 & 9 & 15 & 22 & 3 & 23 & 60 & 58 \\
\hline 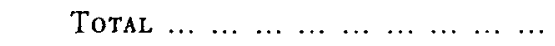 & $(105)$ & $(130)$ & $(321)$ & (63) & $(102)$ & $(148)$ & (334) \\
\hline
\end{tabular}


Así, la aparente contradicción puede deberse al hecho de que votar socialista, así como autodefinirse de izquierda, no es algo que esté ya relacionado con el apoyo a las políticas socialistas tradicionales. En realidad, no existe contradicción entre el hecho de que los españoles generalmente se opongan a las políticas tradicionales de la izquierda y que hayan votado al Partido Socialista, teniendo en cuenta que las políticas seguidas por el Partido Socialista han sido muy heterodoxas y en contradicción con la política socialista tradicional. Parece como si el cambio en el programa socialista hubiese provocado una redefinición de lo que significa ser de izquierdas, y esto es lo que analizaremos en las siguientes páginas.

El análisis de la asociación entre la edad y la educación con el autoposicionamiento ideológico muestra que la educación tiene un efecto pequeño y no significativo, mientras que el efecto de la edad es significativo. Los jóvenes tienden a definirse como de izquierdas, mientras que los de más edad tienden a definirse como de derechas.

Para concluir este apartado descriptivo se pueden resumir así las principales características de la muestra en relación con las variables incluidas en el análisis. Los entrevistados tienden a ser poco religiosos, algo tolerantes con la cohabitación y bastante materialistas en sus objetivos sociales. Las diferencias más significativas, desde un punto de vista sociodemográfico, son las que se observan con la edad, excepto en lo que respecta al índice de postmaterialismo. En esta cuestión es la educación la variable que tiene un valor explicativo mayor.

Por otro lado, los entrevistados parecen no tener opiniones precisas respecto a temas de política económica. Cuando las tienen, éstas tienden a ser algo radicales, pero este tipo de entrevistados radicales representan una minoría respecto al total de la población. Debido probablemente al efecto que estas políticas económicas tienen sobre la estructura de clases, la educación juega un papel explicativo más importante que la edad al diferenciar entre entrevistados; no obstante, también se observan algunos efectos significativos de la edad.

Finalmente, los entrevistados tienden a situarse en el centro/izquierda del espectro político, como se ha ido manifestando en los últimos años.

Para la estimación del modelo factorial presentado en la sección anterior se ha utilizado la submuestra compuesta por aquellos entrevistados que proporcionaron respuestas a todas las preguntas que se han incluido en el análisis, aunque se han replicado los resultados utilizando una matriz de correlaciones basada en los casos que responden a cada par de preguntas. El número total de casos válidos es de 404 , de una muestra total de 1.204. Hemos comparado las dos muestras y, como suele suceder casi siempre, la submuestra de los que responden a todos los items tiene un nivel educativo más alto, es más joven e incluyen una menor proporción de amas de casa. 
Afortunadamente, los resultados de nuestro análisis son iguales, independientemente de que se supriman sólo los que no contestan a cada par de preguntas o todos los que no contestan a una sola de ellas.

\section{Modelo estimado}

Los resultados obtenidos después de estimar el modelo antes descrito para la predicción del autoposicionamiento ideológico de los entrevistados confirman las hipótesis formuladas previamente (figura 2). En primer lugar, obsérvense en la figura 2 las relaciones entre las variables latentes y sus indicadores. La varianza de cada variable latente ha sido fijada en 1 para poder estimar el modelo. Todos los coeficientes van en la dirección esperada y son estadísticamente significativos. Debe tenerse en cuenta que al fijar la varianza del factor latente en 1, la dirección de las dos escalas viene determinada por los coeficientes de regresión entre los factores latentes y sus indicadores. En este caso, el factor que mide las actitudes de progresismo moral y social, así como el que mide las actitudes de izquierdismo económico tradicional, están medidos en escalas que van desde las actitudes más progresistas a las menos progresistas. Cuanto más progresistas son los encuestados en lo moral y en lo social, menor tiende a ser su práctica religiosa, más tiende a aprobar la cohabitación y más postmaterialista tiende a ser. A su vez, los entrevistados más izquierdistas en el sentido económico tradicional son los que tienden a ser más favorables a las nacionalizaciones (de bancos y empresas) y más favorables al intervencionismo gubernamental en la economía.

En segundo lugar, se observa una correlación positiva entre los dos factores. Los entrevistados que sostienen unos puntos de vista más progresistas en lo moral y en lo social suelen ser también los que más apoyan el programa económico tradicional de la izquierda. Esta relación, sin embargo, no es tan fuerte como se podía haber esperado.

Por último, dos factores están relacionados con la variable dependiente, en el sentido que se anticipó en las hipótesis previas. Los entrevistados más progresistas en lo moral y social tienden a autocalificarse más como de izquierdas que los más conservadores. Los entrevistados que son más de izquierdas en el sentido económico tradicional se definen más como de izquierdas que los que son más conservadores en esas cuestiones. Sin embargo, el hallazgo más importante es el de que el efecto de la dimensión moral y social dobla en importancia al de la dimensión económica (véanse los coeficientes estandarizados entre paréntesis).

En conjunto, el modelo explica un muy respetable 47 por 100 de la varianza total en la variable dependiente. Por otra parte, tres índices diferentes de bondad de ajuste sugieren que el modelo estructural reproduce 


\section{FIGURA 2}

Modelo estructural para la estimación de los efectos de cuestiones económiacs y no económicas sobre el autoposicionamiento ideológico (casos completos)

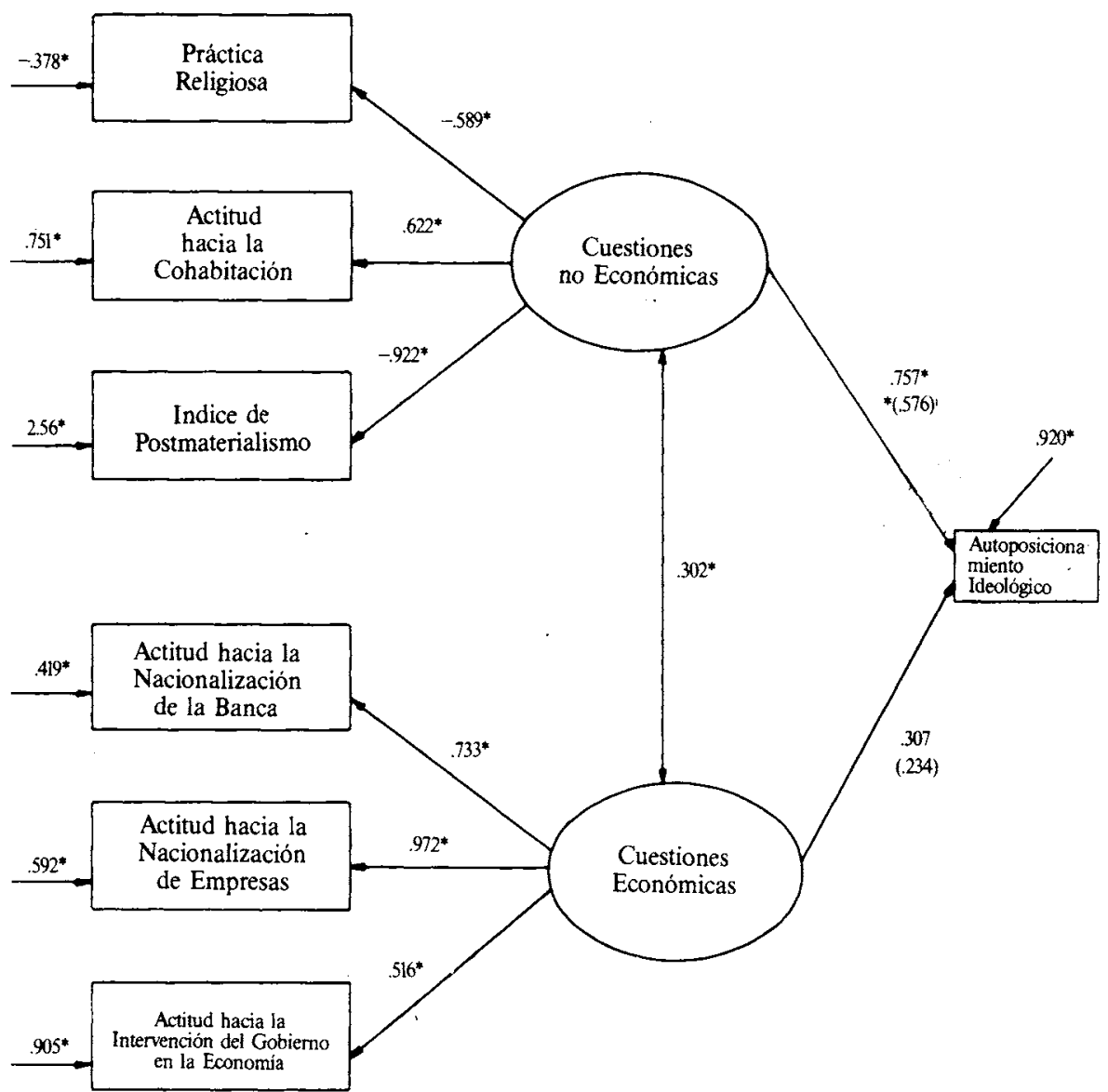

$\mathrm{N}=404$

Coefi. de Det $=468$

Chi-Cuadrado $=12.47 \quad p=409 \quad D F=12$

Indice de Bondad de Ajuste $=.991$

Indice de Bondad de Ajuste Ajustado $=980$

* Significativo al nivel 0,05 .

( ) Coeficientes estandarizados.

Nota: Eliminados los casos que no hayan contestado a todas las preguntas. 
bastante fehacientemente la matriz de varianzas-covarianzas original, lo que indica que se trata de un modelo bastante bueno.

Para confirmar estos resultadós y verificar que pueden ser generalizables a la muestra en su conjunto, se ha estimado el mismo modelo utilizando como input la matriz de correlaciones basada en los casos válidos para cada una de las relaciones bivariadas. Como puede observarse en la figura 3, los coeficientes de las relaciones estructurales son muy similares (compárense los coeficientes de este modelo con los coeficientes estandarizados del modelo original), y la bondad de los índices de ajuste (no tan fiables cuando se usa este procedimiento) sigue siendo elevada, demostrando un buen ajuste. La única diferencia al comparar las figuras 2 y 3 es que en la figura 3 la escala de progresismo moral y social va de menos a más.

Por tanto, estos resultados demuestran que, si bien las dos dimensiones especificadas en este modelo contribuyen a explicar, en la dirección predicha, el autoposicionamiento ideológico, la dimensión moral y social es relativamente más importante. Los resultados ponen de relieve asimismo que las dos dimensiones no están muy relacionadas entre sí. Finalmente, podemos conciuir que las hipótesis de Inglehart sobre la creciente polarización de las poblaciones europeas en dimensiones no económicas pueden aplicarse con éxito a España, donde, de hecho, son ya las que muestran una polarización más importante. Falta por probar si esto ha sido una característica permanente de la política española o si, por el contrario, es más adecuado el postulado de Inglehart sobre la existencia de una tendencia generacional. Si esta última hipótesis es correcta, los factores económicos deberían polarizar más a las generaciones de más edad que a las más jóvenes. $Y$, por el contrario, los factores no económicos deberían polarizar más a las generaciones más jóvenes que a las de más edad. Para probar estas hipótesis, se ha estimado el mismo modelo para tres cohortes distintas. La cohorte más joven corresponde a los nacidos desde 1960. Esta cohorte creció con el desarrollo, y alcanzó los dieciocho años en 1978, año de la aprobación de la Constitución que instauraba la normalidad democrática. Esta cohorte creció bajo las condiciones de seguridad económica mencionadas por Inglehart como causantes de valores postmaterialistas y de una disminución de la importancia tradicional de los valores económicos tradicionales de la izquierda. La segunda cohorte corresponde a aquellos entrevistados que nacieron entre 1936 a 1960. Esta cohorte no vivió la guerra, pero protagonizó la oposición democrática en vida de Franco. Creció bajo las condiciones económicas de miseria de la postguerra, y, por tanto, debería esperarse que sea más materialista y que esté más polarizada en torno a las cuestiones económicas. La tercera cohorte incluye a los nacidos antes de 1936. Estas personas sufrieron la crisis de la guerra y de la postguerra. Por comparación con las cohortes anteriores, ésta debería ser la más materialista y la más polarizada en torno a las cuestiones económicas. 


\section{FIGURA 3}

Madelo estructural para la estimación de los efectos de cuestiones económicas y no económicas sobre el autoposicionamiento ideológico (eliminados los casos en que no se contestó a alguna de cada par de preguntas)

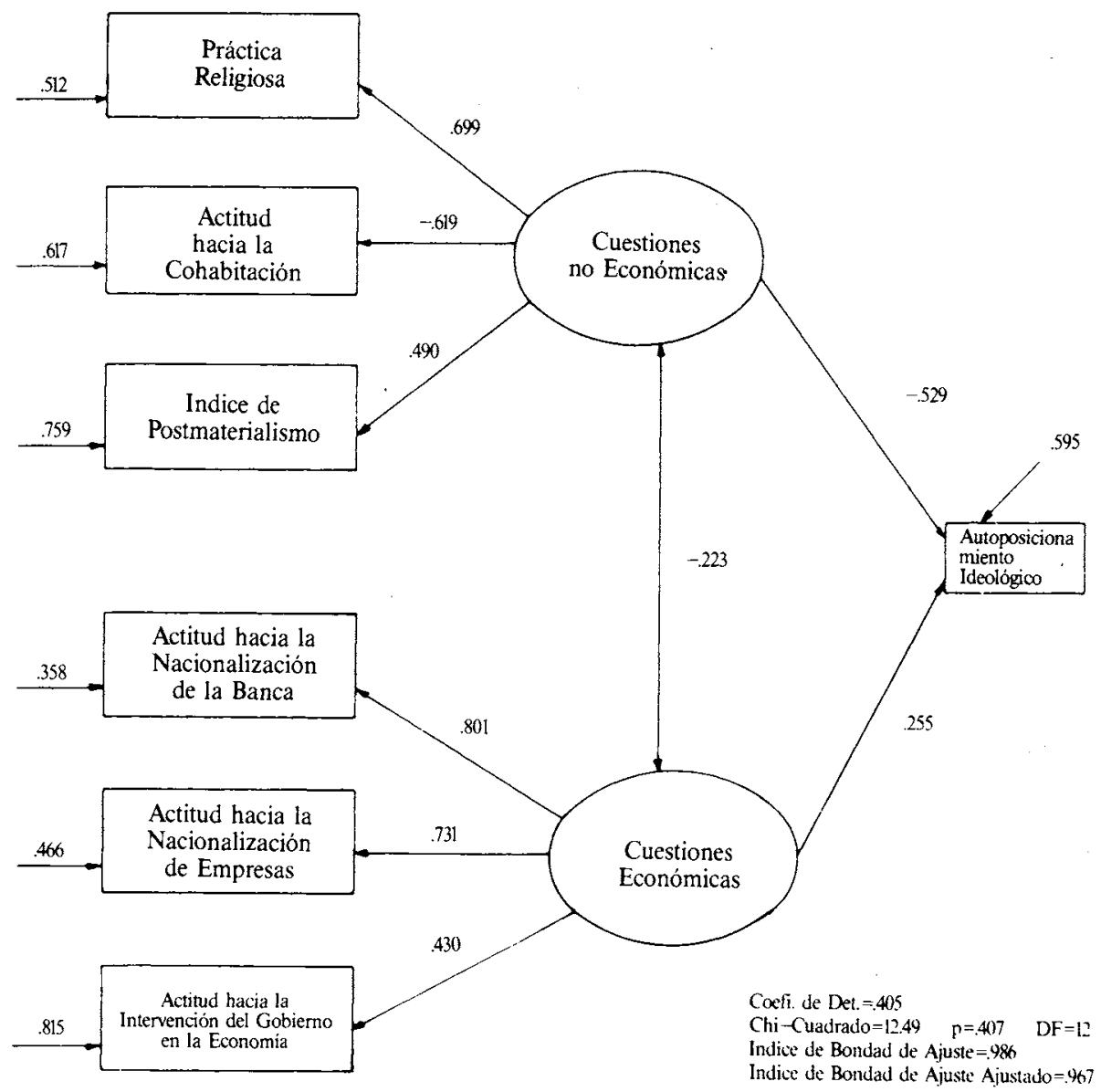

Input: Matriz de correlaciones y eliminación de casos que no hayan contestado alguna de cada par de preguntas.

Nota: Los errores estándar no son fiables con este tipo de input. Por consiguiente, no se ha presentado la significación de los coeficientes.

FueNte: INE, Censo población 1981, Características de la población. 
Como ya se señaló al describir la muestra, hay una asociación muy pequeña y no significativa entre la edad y el postmaterialismo, cuando se controla por la educación. De hecho, este hallazgo confirma la idea de que el postmaterialismo está relacionado con la seguridad económica. Existe una relación negativa significativa entre edad y postmaterialismo, que se explica por el hecho de que el bienestar de las cohortes de más edad —medido por un indicador de status socioeconómico como es la educación- es menor que el de las cohortes más jóvenes. Por esta razón, el efecto de la edad desaparece cuando se controla por la educación.

En el cuadro 12 se resumen los principales resultados de estimar el mismo modelo que predice el autoposicionamiento ideológico para las tres cohortes. Cada uno de ellos ha sido contrastado con los resultados obtenidos al utilizar la matriz de correlaciones que incluye los casos válidos para cada una de las relaciones bivariadas tomadas por separado, no habiéndose observado discrepancias significativas entre ellos. Como ya anticipábamos, los resultados son diferentes para las tres cohortes, aunque la principal discrepancia se observa entre los más jóvenes y las otras dos cohortes. Esto es lo que se esperaba encontrar, dado que la cohorte más joven es la que creció en una sociedad más desarrollada y a'canzó la madurez en una sociedad plenamente democrática. Entre las cohortes más jóvenes, la dimensión económica no tiene el más mínimo efecto polarizador, mientras que la dimensión moral y social tiene un gran efecto polarizador. Entre las cohortes de más edad, sin embargo, la dimensión económica tiene un efecto significativo en la dirección prevista, y la dimensión moral y social tiene un efecto más débil que entre los más jóvenes. A pesar de todo, entre las cohortes de más edad, la dimensión moral y social tiene todavía un efecto de polarización más fuerte que la dimensión económica. Esto puede indicar que el papel político de las cuestiones no económicas ha sido siempre más importante en la polarización de la sociedad que el de las cuestiones económicas. El hecho de que la guerra civil estuviese motivada por cuestiones religiosas y nacionalistas, más que por cuestiones económicas, parece corroborar esta afirmación. Tamb:én podría ocurrir que las generaciones de más edad se estén ajustando ráp:damente a la nueva situación política y económica que prevalece en España. La falta de datos comparables para décadas anteriores no nos permite probar estas hipótesis. De todas formas, las dos explicaciones podrían ser complementarias.

En conjunto, las hipótesis de Inglehart parecen estar confirmadas por los datos. 


\section{CUADRO 12}

Diferencias por cohortes en la correlación entre la dimensión económica y no económica y en los coeficientes de regresión para medir los efectos

de las dimensiones económica y no económica sobre el autoposicionamiento ideológico

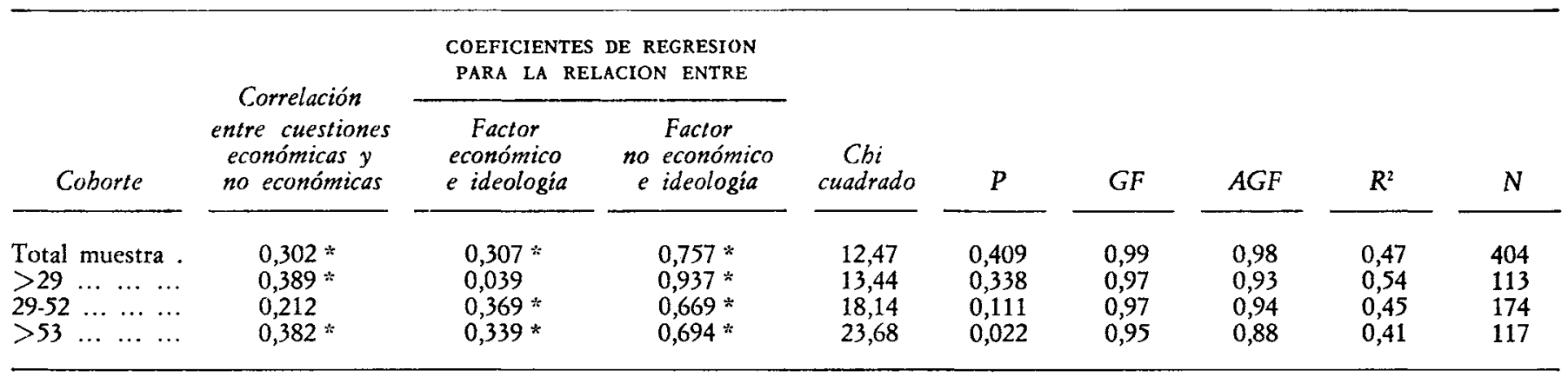

* Significativo en el nivel 0,05 .

Nota: Los coeficientes son el resultado de ajustar el modelo estructural presentado en la figura 1 a tres diferentes cohortes. El input para todos ellos ha sido la matriz de covarianzas. 


\section{Discusión}

Los conceptos de izquierda y derecha han implicado desde la revolución francesa dos concepciones de vida, una favorable al cambio y la otra partidaria de dejar las cosas como están. Durante mucho tiempo, los partidos socialistas y comunistas simbolizaron el cambio, y finalmente se les asignó la etiqueta de izquierda. Sin embargo, el cambio que estos partidos propugnaban fue atractivo para las poblaciones de Europa Occidental, cuando estaban bajo condiciones de bajo bienestar económico y de profundo conflicto de clases. A medida que aumentó el desarrollo económico de estas sociedades, disminuyó la base social proclive a las transformaciones revolucionarias, y otras cuestiones comenzaron a polarizar a la opinión pública. El calificativo de izquierda fue adoptado a la vez por los que defendían el cambio en el sentido económico tradicional y por los que defendían el cambio en base a estas nuevas cuestiones no económicas. Esto es lo que ha ocurrido en España, y es la razón por la que las dos dimensiones incluidas en el análisis explican el autoposicionamiento ideológico. Al mismo tiempo, la dimensión moral y social es dos veces más importante que la dimensión económica. Sin embargo, quienes defienden el cambio en una dimensión no son necesariamente los que defienden el cambio en la otra dimensión. La asociación entre las dos dimensiones existe sin lugar a dudas, y en la dirección prevista, pero no es muy fuerte, lo que indica que probablemente estamos hablando de grupos de individuos algo diferentes.

Parece que el autoposicionarse en la izquierda y el votar al Partido Socialista o al Partido Comunista son hechos que todavía están estrechamente relacionados. La explicación es que los dos partidos han eliminado de sus programas sus viejos dogmas y los han sustituido por políticas económicas que sean aceptables para las clases medias. Más aún, han desviado el debate electoral hacia cuestiones no económicas relacionadas con la familia, con las relaciones internacionales o con la competencia en el terreno económico. Al hacer esto han atraído a un electorado proclive al cambio, pero que se opone a medidas revolucionarias. Este electorado se autodefine como de izquierda porque propugnan un cambio en cuestiones no económicas; votan al Partido Socialista porque su mensaje no es revolucionario, y esto, a su vez, refuerza su autodefinición como de izquierdas, puesto que esta etiqueta ha estado tradicionalmente ligada a los partidos comunistas y socialistas. Estos hallazgos no implican que exista más consenso en las cuestiones no económicas que en las cuestiones económicas tradicionales. Por ejemplo, la opinión pública española está sin duda dividida en cuanto al tema de las nacionalizaciones. Lo que implican los resultados de esta investigación es que las actitudes sobre cuestiones económicas son menos capaces de diferenciar a la izquierda de la derecha que las cuestiones no económicas. Por lo tanto, el debate político debería basarse en las cuestiones no económicas más que en 
las cuestiones económicas tradicionales. Los resultados no implican tampoco que los más jóvenes sean menos favorables a las nacionalizaciones que los de más edad. De hecho, son más favorables. Lo que ocurre es que el apoyo a estas cuestiones económicas entre los más jóvenes, por comparación con las cohortes de más edad, podría estar basado menos en actitudes ideológicas que en una más sólida formación económica.

La principal implicación de este análisis es que, en el futuro, el debate político en España deberá centrarse más en estas cuestiones no económicas que en la confronțación tradicional entre los que están a favor de las nacionalizaciones y los que están en contra. Queda por estudiar si otras cuestiones económicas polarizan a la opinión pública en izquierdas y derechas. Nuestra impresión es que éste no es el caso, puesto que el debate político de los últimos años no se ha centrado en cuestiones específicas de política económica. La información de este artículo y de otros estudios (McDonough et al., 1986) sugiere que la opinión pública española no está muy interesada ni muy informada sobre estos temas. Sin embargo, también es bien sabido que los españoles están muy al tanto de las corruptelas que invaden todas las áreas de la vida española y que impiden el desarrollo de un verdadero sistema meritocrático. Curiosamente, este tema fue uno de los tres más importantes de la campaña socialista de 1982 , pero desde entonces no ha vuelto a ser mencionado.

\section{Conclusión}

En este artículo hemos estudiado el cambio en el significado del autoposicionamiento ideológico en España: Empezamos con una aparente contradicción: los españoles se autopostcionan en la izquierda, pero al mismo tiempo votan a un partido socialista que no prastica una política de izquierda tradicional. La respuesta a esta contradiçón se ha investigado a nivel teórico, empírico y político. Siguiendo la teoría de Inglehart sobre la importancia decreciente del determinismo econémicr: hemos argumentado que el significado de ser de izquierdas o de derechas ha cambiado porque la sociedad española se ha desarrollado. Este desarrollo ha implicado que las transformaciones revolucionarias pierlan sw atractivo y que nuevas fuentes no económicas de polarización política hayan adquirido más importancia. Para probar esta hipótesis se ha procedido en dos etapas: primero, mediante técnicas de análisis factorial confirmatorio hemos mostrado que la dimensión no económica tiene un gran efecto en el autoposicionamiento ideológico, mientras que la dimensión económica tiene un efecto menor, pero todavía significativo. En segundo lugar, mediante las mismas técnicas hemos demostrado que la dimensión moral y social es más importante entre las generaciones que crecieron en el período de crecimiento económico y de transición política en 
España que entre las generaciones de más edad, que protagonizaron o crecieron durante la guerra civil y durante el período de penuria de la postguerra.

Finalmente, en el nivel político, hemos visto que el éxito del Partido Socialista para atraer a estas nuevas camadas de electores de izquierda se debe a la moderación de su mensaje, y a haber suprimido de su programa político todo lo que estuviese asociado con la vieja izquierda.

En conjunto, las hipótesis de Inglehart sobre la decreciente significación política de las viejas políticas de izquierda parecen bien probadas, en el nivel transversal, y cuando se comparan diferentes cohortes. Sin embargo, se necesitan más investigaciones para poner a prueba otras cuestiones económicas y no económicas que puedan estar polarizando desde el punto de vista político a la opinión pública en los países de Europa Occidental.

\section{BIBLIOGRAFIA}

Alvira Martín, F; Horter, K. Peña, M., y Espinosa, L. (1978): Partidos Políticos $e$ Ideologías en España, Madrid: Centro de Investigaciones Sociológicas.

CIS (1976): La Reforma Política y la Ideologia Política de los Españoles, Madrid: Centro de Investigaciones Sociológicas.

- (1986): «La Evolución de la Intención de Voto y Otros Indicadores Políticos: 1979. 1982 y 1983-1986», Revista Española De INVESTigaciones Sociológicas, 28: 305-321, y 35: 269-340.

Deutsch, E.; Lindon, D., y Weill, P. (1966): Les Familles Palitiques d'Aujourd'bui en France, París: Minuit.

Díez Nicolás, J. (1978): «Evolución de la Ideología de los Españoles en el Proceso Constituyente», en Club Siglo XXI, Constitución, Economía y Regiones, Madrid: Iberoamericana de Ediciones, pp. 137-162.

- (1984): «Análisis de las Elecciones Generales del 28 de octubre de 1982», en Club Siglo XXI, Razón y Convivencia en la Poltitica Española, Madrid: Unión Editorial, pp. 213-234.

- (1986): «Análisis y Consecuencias de las Elecciones Generales de 1986», Cuenta y Razón, 25: 75-84.

Downs, A. (1957): An Economic Theory of Democracy, Nueva York: Harper and Row.

García Ferrando, M. (1984): «Reforma y Cambio Social: Lo que entienden los españoles por Izquierda en Politica», Sistema, 58: 105-120.

Inglemart, R. (1977): The Silent Revolution, Princeton: Princeton University Press.

- (1989): Cultural Change, Princeton: Princeton University Press (en proceso de traducción al castellano por el Centro de Investigaciones Sociológicas).

IngleharT, R., y KLINGEMANN, H. D. (1976): «Party Identification Ideological Preference, and the Left/Right Dimension Among Western Mass Publics», en Party Identitication and Beyond, editado por Ian Budge, Ivor Crewe y Dennis Farlie, Londres: John Wiley, pp. 243-276.

INGIEHART, R., y SIDJANSKI, D. (1976): «The Left, the Right, the Establishment, and the Swiss Electorate», en Party Identification and Beyond, editado por Ian Budge, Ivor Crewe y Dennis Farlie, Londres: John Wiley, pp. 225-242.

JoresKoG, K. J., y Sorbom, D. (1983): LISREL V User's Guide, Chicago: International Educational Services. 
Kuingemann, H. D. (1976): «Measuring Ideological Conceptualizations", en Political Ac. tion, editado por Samuel H. Barnes y Max Kaase, Beverly Hills: Sage, pp. 215-254.

LAmBert, R. D. (1983): «Question Design, Response Set, and the Measurement of Left/ Right Thinking in Social Research», Canadian Journal of Political Science, 16: 135-145.

Lambert, R. D.; Curtis, J. E.; Brown, S. D., y Kay, B. J. (1986): "In Search of Left/ Right Beliefs in the Canadian Electorate», Canadian Journal of Political Science, 19: 705-729.

McDonough, P.; Barnes, S. H., y López Pina, A. (1985): «Economic Policy and Public Opinion in Spain», American Journal of Political Science, 30: 446-480. 